\title{
Giant Ovarian Cyst That May Be Confused With Mesentery Cyst
}

\author{
Ilhan Paltacia, e, Guvenc Diner ${ }^{\mathrm{b}}$, Fatma Ferda Kartufan ${ }^{\mathrm{c}}$, Mehmet Urfalioglu ${ }^{\mathrm{d}}$
}

\begin{abstract}
Ovarian cysts may reach giant size and may usually be confused with intraabdominal mesentery cysts, acid accumulation or inclusion cysts. They usually appear with intestinal system findings and abdominal distention. Computed tomography (CT) may be used for the detection of size and origin of the cysts. Midline laparotomy should be preferred due to the likelihood of malignity and confusion with other intraabdominal pathologies. Treatment protocol is determined based upon the patient's fertility. A 52-year-old female patient, who was admitted with constipation and abdominal distention, and was detected to have a mucinous cystadenoma measuring $25 \mathrm{~cm}$ originating in the left ovary, is presented in this paper.
\end{abstract}

Keywords: Giant cyst; Laparotomy; Ovary

\section{Introduction}

Ovarian cysts rarely reach giant size although they are common. Cysts that reach large size may be confused with mesentery cysts, peritoneal inclusion cysts or loculated acid accumulation [1]. Mucinous tumors of the ovary account for $10 \%$ of ovarian neoplasms. Among all ovarian tumors, approximately $80 \%$ are benign, $10 \%$ are borderline and $10 \%$ are malignant. Eighty percent of the cases are unilateral

\footnotetext{
Manuscript accepted for publication April 11, 2014

${ }^{a}$ Department of General Surgery, Gediz State Hospital, Kutahya, Turkey

${ }^{\mathrm{b}}$ Department of General Surgery, Simav State Hospital, Kutahya, Turkey

${ }^{\mathrm{c}}$ Department of Anesthesiology and Reanimation, Gediz State Hospital, Kutahya, Turkey

${ }^{\mathrm{d} D e p a r t m e n t ~ o f ~ G y n e c o l o g y ~ a n d ~ O b s t e t r i c s, ~ G e d i z ~ S t a t e ~ H o s p i t a l, ~}$ Kutahya, Turkey

${ }^{e}$ Corresponding author: Ilhan Paltaci, Department of General Surgery, Gediz State Hospital, Kutahya, Turkey. Email: i.paltaci@hotmail.com
}

doi: http://dx.doi.org/10.14740/jmc1776w and may reach the size that fills the whole abdomen. Mucinous cystadenoma is more common among young women and usually measures $15-30 \mathrm{~cm}$. Mucinous cystadenomas reaching $60 \mathrm{~cm}$ have been reported in the literature. The cyst is usually divided into several chambers and consists of clear mucoid and viscous fluid. Enlargement of abdominal cicumference, gastrointestinal complaints with unexplained etiology, a sense of mass and pain are the most common complaints. Surgery is the first choice of treatment [2-4].

\section{Case Report}

A 52-year-old female patient was admitted to our clinic with complaints of abdominal distention, firmness and constipation. She had a history of diabetes mellitus and hypertension, her obstetrics anemnesis included five pregnancies (three deliveries and two abortions) and she has been in the menopausal period for 10 years. Her physical examination revealed a mass lesion in the left pelvic region with unclear borders. Ultrasonographic examination revealed a cystic lesion measuring $150 \mathrm{~mm}$ in the pelvic region at the midline. CT of her abdomen reported a cystic lesion measuring $17 \times$ $10 \times 13 \mathrm{~cm}$ filling the left lower quadrant and suggesting to originate primarily from the ovary (Fig. 1). The patient was prepared for operation with a prediagnosis of an ovarian cyst and mesentery cyst. Laboratory tests revealed no pathologic

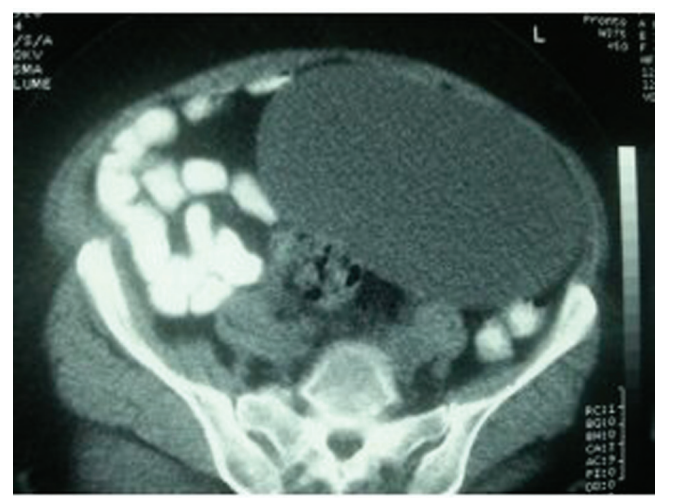

Figure 1. Computered tomography (CT) image of the cyst. 


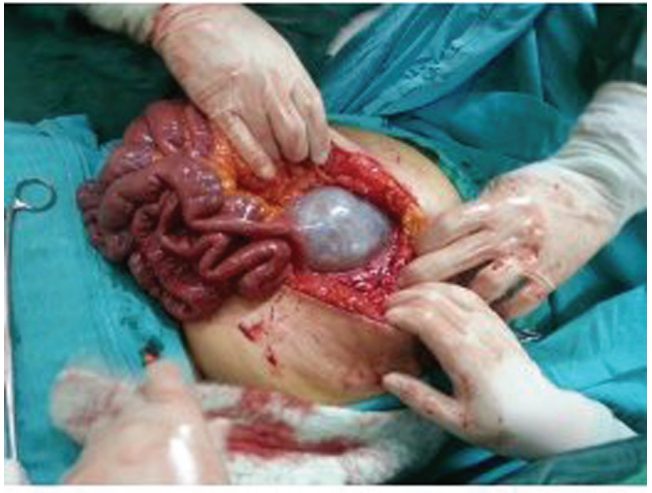

Figure 2. Intraabdominal appearance of the cyst.

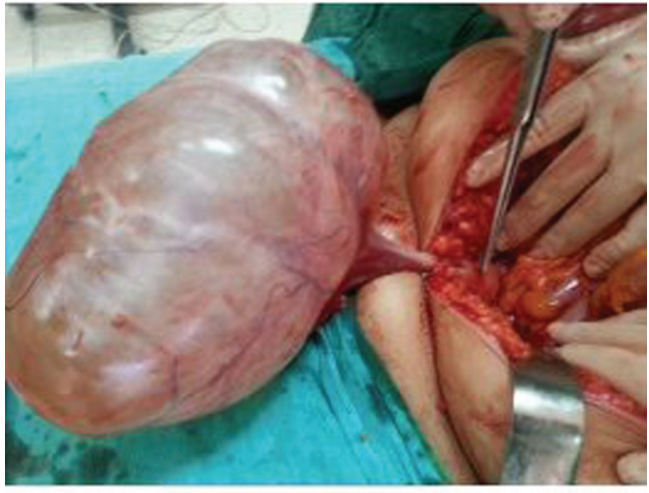

Figure 4. The association of the cyst with the uterus. findings. CA125 and CA15.3 were normal. A pure cystic mass lesion measuring $25 \mathrm{~cm}$, originating from the pelvic region and extending to midline of the abdomen and crossing the umbilicus was detected in the patient, who was operated under general anesthesia (Fig. 2,3). The cysts were seen to originate from the left ovary (Fig. 4). The patient underwent left salpingo oophorectomy and cystectomy as the ovarian tissue could not be detected clearly enough to be preserved. The patient, whose pathology examination results were reported as a mucinous cystadenoma measuring $25 \times 17 \times 10$ $\mathrm{cm}$, was discharged unproblematically.

\section{Discussion}

Two-thirds of ovarian cysts are seen during the reproductive years. Of them, $80-85 \%$ are benign [5]. While unilateral, mobile, cystic and smooth masses are likely to be benign, bilateral, solid, fixed and irregular masses are usually malignant [6]. Cysts originating from mesentery and omentum may be confused with loculated acid accumulations and lympangiomas. Giant ovarian cysts have rarely been reported together with widepread use of imaging methods. Symmonds et al reported nine ovarian cysts weighing 90 - $130 \mathrm{~kg}$ [7]. Dolan

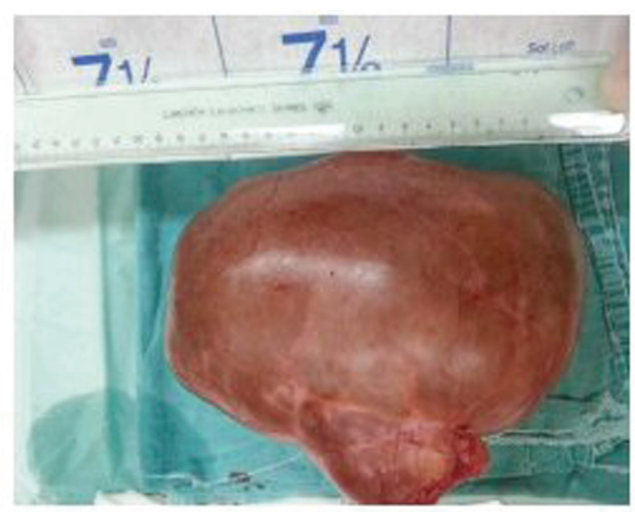

Figure 3. Appearance of the cyst after excision. et al recently reported giant ovarian cysts weighing less than $20-30 \mathrm{~kg}$ and managed laparoscopically [8]. The patient may be admitted to the clinic with complaints of abdominal pain, nausea, vomiting and constipation due to bleeding, rupture, and/or obstruction depending on the location, size of the cysts and compression [9]. The patient was admitted to our clinic with complaints of constipation. Upon physical examination, a sense of mass with unclear borders palpated in the pelvic region was detected.

Ultrasonography is useful for discrimination of solid and cystic intraabdominal masses. CT may be used for determination of borders and the origin of the mass lesion [10]. Our patient was evaluated initially with ultrasonography, and the mass lesion was seen to be cystic. CT revealed intraabdominal extension and the potential origin of the mass. Laparotomy was performed with a midline incision due to a potential non-ovarian pathology. Upon exploration, the giant cyst was seen to originate from the left ovary, thus cystectomy was performed together with left salpingo ooforectomy, considering the fertility of the patient and as the ovarian tissue to be preserved could not be clearly determined.

\section{Conclusion}

In conclusion, giant ovarian cysts are rarely encountered. Often, they may be confused with mesentery cysts and omentum cysts. Therefore, a midline laparotomy incision is preferred. The fertility of the patient should be considered when making a treatment plan. Although giant ovarian cysts always require resection, ooforectomy should usually be performed, due to suspicion of malignity.

\section{References}

1. Mikos T, Tabakoudis GP, Pados G, Eugenidis NP, Assimakopoulos E. Failure of ultrasound to diagnose a giant ovarian cyst: a case report. Cases J. 2009;2:6909.

2. Cicek MN, Akyurek C, HaberalA, Celik C. Kadin Has- 
taliklari ve Dogum Bilgisi. Overin benign hastaliklari, Endometriozis. Oncu Basimevi. 2006:854- 55, 899- 910.

3. Soslow RA. Histologic subtypes of ovarian carcinoma: an overview. Int J Gynecol Pathol. 2008;27(2):161-174.

4. Hart WR. Mucinous tumors of the ovary: a review. Int J Gynecol Pathol. 2005;24(1):4-25.

5. Berek SJ. Novak's Gynecology. In: Berek JS, Adashi EY, Hillard PA (Eds) Baltimore: Lippincott Williams \& Wilkins 1996; 3p. 361-62.

6. Bell DA. Nomenclature of borderline epithelial tumors of the ovary. Curr Controver 1997;2:144-153.

7. Symmonds RE, Spraitz AF, Jr., Koelsche GA. Large
Ovarian Tumor. Report of a Case. Obstet Gynecol. 1963;22:473-477.

8. Dolan MS, Boulanger SC, Salameh JR. Laparoscopic management of giant ovarian cyst. JSLS. 2006;10(2):254-256.

9. Pisano G, Erdas E, Parodo G, Martinasco L, Pomata M, Daniele GM. [Acute abdomen due to rupture of mesenteric cysts. Observations on a clinical case and review of the literature]. Minerva Chir. 2004;59(4):405-411.

10. Zamir D, Yuchtman M, Amar M, Shoemo U, Weiner P. [Giant mesenteric cyst mimicking ascites]. Harefuah. 1996;130(10):683-684, 727. 